\title{
ANALISIS LAPORAN KEUANGAN DENGAN MENGGUNAKAN METODE RGEC PADA PERUSAHAAN PERBANKAN KONVENSIONAL
}

\author{
Mario Viegas, Suklimah Ratih \\ Fakultas Ekonomi, Universitas Widya Kartika \\ Email: marioliemada@gmail.com, ratihratih177@gmail.com
}

\begin{abstract}
In choosing a banking company to use the producers and services of the banking company. It is important to note that the selection of a bank is not only based of the fame on the bank or the presence of acquaintances or family members who work in the company. However, the selection of a good and correct bank is to look at the soundness of the bank. Therefore, this study aims to determine the soundness of conventional banking companies listed on the Indonesia stock exchange in 2016 - 2019. The method used in sampling is purposive sampling, especially for banks that are included in book 4 so that researchers get 6 banking companies that in accordance with the criteria in 2016 - 2019. The research technique used by the researcher is to calculate the ratio based on the RGEC method. The result of this study indicates that 3 out of 6 conventional banks have a very healthy level of health and the other 3 banks have a healthy level of health.
\end{abstract}

Keyword: RGEC Method; Banking soundness level; Conventional Banking and Bank Book 4.

\begin{abstract}
Abstrak
Dalam memilih perusahaan perbankan untuk menggunakan produk dan jasa perusahaan perbankan tersebut, perlu diketahui bahwa pemilihan bank tidak hanya dari ketenaran bank tersebut atau juga dari ada kenalan atau pun keluarga yang bekerja dalam perusahaan tersebut. Akan tetapi, pemilihan bank yang baik dan benar adalah melihat tingkat kesehatan bank tersebut. Oleh sebab itu penelitian ini bertujuan untuk mengetahui bagaimana menentukan tingkat kesehatan perusahaan perbankan konvensional yang terdaftar di Bursa Efek Indonesia Pada Tahun 2016 - 2019. Metode yang digunakan dalam pengambilan sampel adalah Purposive Sampling khususnya untuk bank yang termasuk buku 4 sehingga peneliti mendapatkan 6 perusahaan perbankan yang sesuai dengan kriteria pada tahun 2016 - 2019. Teknik penelitian yang digunakan peneliti adalah dengan menghitung rasio berdasarkan Metode RGEC. Hasil penelitian ini menunjukkan bahwa 3 dari 6 perbankan konvensional memiliki tingkat kesehatan yang sangat sehat dan 3 perbankan lainnya memiliki tingkat kesehatan yang sehat.
\end{abstract}

Kata Kunci: Metode RGEC; Tingkat Kesehatan Perbankan; Bank Konvensional 


\section{Pendahuluan}

Dunia perbankan pada zaman ini sangat begitu banyak peminatnya dari segi masyarakat dengan semua kalangan, tipe masyarakat dalam memilih bank dalam menyimpan uang nasabah tersebut tergantung dari pemikiran masyarakat tersebut ada yang memilih karena nilai bunga yang tinggi, kenal dengan salah satu pegawai bank tersebut dan sebagainya. Akan tetapi pemilihan bank yang baik dan benar dengan melihat dari nilai-nilai yang ada di dalam bank tersebut. Dalam Undang-Undang Republik Indonesia Nomor 10 tahun 1998 tentang perbankan menyebutkan bahwa bank adalah badan usaha yang menghimpun dana dari masyarakat dalam bentuk simpanan dan menyalurkannya kepada masyarakat dalam bentuk kredit dan atau bentuk-bentuk lainnya dalam rangka meningkatkan taraf hidup rakyat banyak (Situmorang, 2012).

Selain berfungsi sebagai lembaga perantara, bank juga berperan sebagai pelaksana lalu lintas pembayaran, stabilisator moneter, dan juga sebagai dinamisator perekonomian pada suatu pembangunan nasional dalam rangka meningkatkan pemerataan, pertumbuhan ekonomi, dan stabilitas nasional ke arah peningkatan taraf hidup rakyat banyak. Otoritas Jasa Keuangan (OJK) mengungkapkan dalam rasio profitabilitas dari rasio ROA (Return on Assets) dari industri perbankan menurun tipis selama 2016 (Izza, 2017).

Hal ini karena bank perlu menambah pemasukan biaya pencadangan akibat meningkatnya rasio kredit bermasalah (Non Performing Loan/NPL). Dari Otoritas Jasa Keuangan (OJK) mencatat kredit perbankan sepanjang tahun 2016 tumbuh lebih lamban dibandingkan tahun 2015 yang di kisaran 10\%. Bank Indonesia (BI) mengungkapkan, stabilitas sistem keuangan tetap terjaga di tengah intermediasi perbankan yang belum kuat. Dari pihak Bank Indonesia (BI) menyatakan bahwa stabilitas keuangan tercermin pada rasio permodalan bank yang cukup tinggi pada level 23,2\%. Sementara itu, sejalan dengan upaya penguatan manajemen risiko kredit perbankan pada rasio kredit bermasalah / Non Performing Loan/NPL) berada pada level 2,98\% (Gross) atau 1,25\% (Net) lebih rendah dibandingkan pada tahun 2017 yaitu sebesar 2,96\% (Gross) atau 1,29 (Net) (Syahid, 2016).

Menurut Dewan Komisioner OJK Muliaman Hadad di Jakarta, mengatakan bahwa indikator Return On Asset (ROA) pada tahun 2016 menurun tipis dibandingkan tahun 2015 karena kebutuhan mitigasi risiko terhadap aset perbankan mengingat NPL yang terus menunjang bank kan mencapai persentase yang cukup tinggi. Namun pada akhirnya pada akhir desember NPL perbankan telah membaik menjadi lebih tinggi. Laporan Keuangan adalah data informasi yang terdapat di semua perusahaan yang berisikan tentang bagaimana kondisi perusahaan dalam 1 tahun terakhir yang menjalankan bisnis perusahaan itu (Hadad, 2017).

Laporan keuangan bank menunjukkan kondisi keuangan bank secara keseluruhan, baik dari posisi aktiva, pasiva, pendapatan dan biaya yang telah dilaksanakan oleh bank. Laporan keuangan juga memberikan informasi tentang hasil-hasil usaha yang diperoleh 
bank dalam suatu periode tertentu dan biaya-biaya atau beban yang telah perusahaan keluarkan untuk segala kegiatan atas nama perusahaan. Laporan keuangan terbagi atas 5 yaitu:

a. Laporan Laba Rugi

b. Laporan Neraca

c. Laporan Perubahan Ekuitas

d. Laporan Arus Kas

e. Catatan Atas Laporan Keuangan, dan

f. Laporan Keuangan Gabungan dan Konsolidasi (Khusus Perbankan)

Dalam penelitian ini peneliti menggunakan semua laporan keuangan karena ada beberapa pos akun yang nominal atau persentase nya terdapat di masing-masing laporan keuangan tersebut. Dengan banyaknya perusahaan yang ada di Indonesia dan yang telah terdaftar di Bursa Efek Indonesia (BEI) maka akan sangat sulit untuk mempertahankan ketenaran suatu perusahaan dalam waktu ini dengan banyaknya persaingan yang ketat, dengan begitu perusahaan harus melakukan kinerja yang baik agar kinerja satu perusahaan dapat dinilai sangat baik dan dapat menjaga konsistensi nya berada dalam pasar indonesia. Perusahaan akan membuat kinerja yang baik apabila manajer perusahaan mengambil keputusan yang tepat dengan melihat apakah tingkat kesehatan perusahaan sudah bagus untuk mengambil keputusan (Manoppo \& Arie, 2016).

Manajemen perusahaan harus pintar dalam mengelola sumber daya yang ada di dalam sebuah perusahaan, agar perusahaan tiap tahun ke tahun tidak mengalami kondisi keuangan yang kurang baik/buruk. Dengan melihat progres nya adalah di dalam laporan keuangan merupakan tolak ukur perusahaan dalam melihat pengelolaan perusahaan sudah baik atau belum. Perbankan harus selalu dinilai tingkat kesehatan perusahaan nya agar tetap stabil atau meningkat dalam melayani para nasabah nya. Bank yang tidak sehat bukan banyak dapat membahayakan perusahaan bank itu tersebut, tetapi dapat membahayakan pihak-pihak yang terlibat di dalamnya. Untuk menilai tingkat kesehatan perusahaan perbankan dapat dilihat dari beberapa metode yaitu Metode CAMELS dan Metode RGEC (Riniwati, 2016).

Namun seiring berjalannya waktu Bank Indonesia telah menerbitkan Surat Edaran yang mengatur tentang bagaimana cara menilai tingkat kesehatan dengan menggunakan metode yang seharusnya. Peraturan Bank Indonesia No. 13/1/PBI/2011 yang dalam melakukan penilaian nya menggunakan pendekatan (Risk Profile, Good Corporate Governance, Earning dan Capital) yang menggantikan Peraturan Bank Indonesia sebelumnya yaitu Peraturan Bank Indonesia No. 6/10/PBI/2004 dengan faktor - faktor penilaian nya di golong kan dalam 6 (enam) faktor yang disebut CAMELS (Capital, Asset Quality, Management, Earnings, Liquidity dan Sensitivity to Market Risks) (Husein \& Hasib, 2016).

Tingkat kesehatan perusahaan atau secara umum yang kita ketahui adalah hasil laporan keuangan sebuah perusahaan yang mengatakan perusahaan itu laba atau rugi. Tingkat kesehatan perusahaan bisa dihitung melalui rasio dan ada beberapa metode yang akan digunakan tergantung dengan teori yang akan dilakukan peneliti. Pada saat 
ini peneliti melakukan penelitian dengan menggunakan Metode RGEC dengan perusahaan perbankan yang ada di Bursa Efek Indonesia, Metode RGEC yang digunakan peneliti adalah metode yang akan akan menilai kinerja perusahaan perbankan dengan cara menggunakan Risk Profile, Good Corporate Governance, Earnings dan Capital (Alawiyah, 2016). Dengan menggunakan cara yang sudah dideskripsikan oleh peneliti maka hasil dari penilaian tersebut dapat menentukan kinerja perusahaan tersebut.

Pada Undang-Undang Nomor 7 tahun 1992 tentang perbankan yang telah diubah menjadi Undang-Undang Nomor 10 Tahun 1998, Bank wajib memelihara kesehatannya. Hal ini karena kesehatan bank merupakan cerminan kondisi dan kinerja bank yang merupakan sarana bagi otoritas pengawas dalam menetapkan strategi dan fokus pengawasan terhadap bank. Selain itu, kesehatan bank juga menjadi kepentingan semua pihak terkait baik dari segi pemilik, pengelola, masyarakat yang menggunakan jasa bank tersebut, serta Bank Indonesia sebagai pembina dan pengawas bank-bank.

\section{Metode Penelitian}

Peneliti menggunakan metode penelitian pendekatan kualitatif. Penelitian kualitatif merupakan teknik analisis data yang menggunakan deskriptif atau menggunakan kalimat yang sifatnya menjelaskan sesuatu sehingga menghasilkan gambaran yang diinginkan peneliti. Sedangkan pendekatan kuantitatif adalah teknik analisis yang berfokus pada data yang bersifat numeric dari awal pengumpulan data, menganalisis dan mendapatkan hasil yang diinginkan. Data kuantitatif diperoleh peneliti dari laporan keuangan yang dipublikasikan perusahaan perbankan yang terdaftar di Bursa Efek Indonesia (BEI) 2016-2019. Sedangkan data kualitatif didapatkan peneliti setelah perhitungan data kuantitatif telah dilakukan (Anggito \& Setiawan, 2018).

Populasi merupakan subjek penelitian. maka bisa disimpulkan bahwa populasi dari penelitian kali ini adalah perusahaan yang bersektor perbankan yang terdaftar di Bursa Efek Indonesia. Populasi dalam penelitian ini adalah perusahaan perbankan yang terdaftar di Bursa Efek Indonesia tahun 2016 - 2019. Pada penelitian ini, peneliti menggunakan teknik sampling dengan pendekatan non Probability sampling (Rachmawati, 2019). Teknik non probability sampling adalah Purposive sampling yang di mana teknik ini memilih anggota sampel dari populasi yang ditentukan oleh peneliti semata (subjektif) yaitu Bank yang termasuk dalam Buku 4 saja. Peneliti memilih teknik Purposive Sampling ini karena semua sampel tidak memiliki ketentuan yang peneliti inginkan atau yang sudah peneliti tentukan, maka dari itu peneliti menentukan teknik Purposive Sampling dengan kriteria-kriteria yang peneliti inginkan (Budijanto, 2013).

Peneliti berfokus pada perusahaan perbankan konvensional Bank Buku 4 20162019 yang telah membagikan laporan keuangan secara lengkap, sehingga peneliti dapat mengumpulkan data-data perusahaan yang telah ditentukan oleh peneliti dengan menggunakan metode RGEC. Laporan keuangan perusahaan dapat diperoleh di Bursa Efek Indonesia dengan perusahaan yang bersektor di bidang perbankan konvensional. 


\section{Hasil dan Pembahasan}

\section{Net Performing Loan}

Tabel 1. Perhitungan dengan menggunakan NPL

\begin{tabular}{|l|l|c|c|c|c|c|c|c|c|}
\hline \multirow{2}{*}{ No. } & \multirow{2}{*}{ Jenis Bank Konvensional } & \multicolumn{4}{|c|}{ Hasil Perhitungan NPL } & \multicolumn{5}{c|}{ Peringkat } \\
\cline { 3 - 11 } & & 2016 & 2017 & 2018 & 2019 & 2016 & 2017 & 2018 & 2019 \\
\hline 1. & Bank BCA & $1 \%$ & $1 \%$ & $1 \%$ & $1 \%$ & 1 & 1 & 1 & 1 \\
\hline 2. & Bank BRI & $2 \%$ & $2 \%$ & $2 \%$ & $3 \%$ & 2 & 2 & 2 & 2 \\
\hline 3. & Bank CIMB Niaga & $4 \%$ & $4 \%$ & $3 \%$ & $3 \%$ & 2 & 2 & 2 & 2 \\
\hline 4. & Bank Mandiri & $4 \%$ & $3 \%$ & $3 \%$ & $2 \%$ & 2 & 2 & 2 & 2 \\
\hline 5. & Bank BNI & $3 \%$ & $6 \%$ & $6 \%$ & $7 \%$ & 2 & 3 & 3 & 3 \\
\hline 6. & Bank Danamon & $3 \%$ & $2 \%$ & $3 \%$ & $3 \%$ & 2 & 2 & 2 & 2 \\
\hline
\end{tabular}

Sumber : Diolah Pencliti

Pada Tabel 1 merupakan hasil perhitungan dengan menggunakan rumus NPL dan telah diurutkan berdasarkan peringkat masing - masing bank. Dan diketahui bahwa peringkat pertama yang memiliki tingkat kesehatan yang sangat sehat pada tahun 2016 adalah Bank BCA. Peringkat kedua pada tahun 2016 yang artinya perusahaan dengan tingkat kesehatan yang sehat adalah Bank BRI, Bank CIMB Niaga, Bank Mandiri, Bank BNI, dan Bank Danamon. Untuk tahun 2017 diketahui bahwa peringkat pertama yang memiliki tingkat kesehatan yang sangat sehat pada tahun 2017 adalah Bank BCA. Peringkat kedua pada tahun 2017 yang artinya perusahaan dengan tingkat kesehatan yang sehat adalah Bank BRI, Bank Mandiri, Bank CIMB Niaga, Bank Danamon.

Kemudian peringkat ketiga pada tahun 2017 yang memiliki tingkat kesehatan yang cukup sehat adalah Bank BNI. Kemudian untuk tahun 2018 diketahui bahwa peringkat pertama yang memiliki tingkat kesehatan yang sangat sehat adalah Bank BCA. Kemudian peringkat kedua yang memiliki tingkat kesehatan yang sehat adalah Bank BRI, Bank Mandiri, Bank CIMB Niaga, dan Bank Danamon. Kemudian untuk peringkat ketiga dengan tingkat kesehatan yang sehat Bank BNI. Dan Kemudian untuk tahun 2019 diketahui bahwa peringkat pertama yang memiliki tingkat kesehatan yang sangat sehat adalah Bank BCA. Peringkat kedua yang artinya perusahaan dengan tingkat kesehatan yang sehat adalah Bank BRI, Bank Mandiri dan Bank Danamon. Kemudian peringkat ketiga yang memiliki tingkat kesehatan yang cukup sehat adalah Bank Negara Indonesia. 


\section{Loan Deposit Ratio}

Tabel 2. Perhitungan dengan menggunakan LDR

\begin{tabular}{|c|c|c|c|c|c|c|c|c|c|}
\hline \multirow{2}{*}{ No. } & \multirow{2}{*}{ Jenis Bank Konvensional } & \multicolumn{4}{|c|}{ Hasil Perhitungan LDR } & \multicolumn{4}{|c|}{ Peringkat } \\
\hline & & 2016 & 2017 & 2018 & 2019 & 2016 & 2017 & 2018 & 2019 \\
\hline 1 . & Bank BCA & $76 \%$ & $78 \%$ & $83 \%$ & $82 \%$ & 2 & 2 & 2 & 2 \\
\hline 2. & Bank BRI & $69 \%$ & $71 \%$ & $72 \%$ & $71 \%$ & 1 & 1 & 1 & 1 \\
\hline 3. & Bank CIMB Niaga & $80 \%$ & $79 \%$ & $79 \%$ & $79 \%$ & 2 & 2 & 2 & 2 \\
\hline 4 & Bank Mandiri & $93 \%$ & $88 \%$ & $96 \%$ & $98 \%$ & 3 & 3 & 3 & 3 \\
\hline 5. & Bank BNI & $79 \%$ & $76 \%$ & $72 \%$ & $76 \%$ & 2 & 2 & 1 & 2 \\
\hline 6. & Bank Danamon & $86 \%$ & $86 \%$ & $88 \%$ & $89 \%$ & 3 & 3 & 3 & 3 \\
\hline
\end{tabular}

Sumber: Diolah Peneliti

Pada Tabel 2 merupakan hasil perhitungan dengan menggunakan rumus LDR dan telah diurutkan berdasarkan peringkat masing - masing bank. Dan dapat diketahui bahwa peringkat pertama yang memiliki tingkat kesehatan yang sangat sehat pada tahun 2016 adalah Bank BRI. Peringkat kedua pada tahun 2016 yang artinya perusahaan dengan tingkat kesehatan yang sehat adalah Bank Negara Indonesia, Bank BCA dan Bank CIMB Niaga. Kemudian peringkat ketiga pada tahun 2016 yang memiliki tingkat kesehatan yang cukup sehat adalah Bank Mandiri dan Bank Danamon. Untuk tahun 2017 diketahui bahwa peringkat pertama yang memiliki tingkat kesehatan yang sangat sehat pada tahun 2017 adalah Bank BRI.

Peringkat kedua pada tahun 2017 yang artinya perusahaan dengan tingkat kesehatan yang sehat adalah Bank BNI, Bank BCA dan Bank CIMB Niaga. Kemudian untuk peringkat ketiga pada tahun 2017 dengan tingkat kesehatan yang cukup sehat adalah Bank Mandiri dan Bank Danamon. Kemudian untuk tahun 2018 diketahui bahwa peringkat pertama yang memiliki tingkat kesehatan yang sangat sehat adalah Bank BRI, dan Bank BNI.

Peringkat kedua yang artinya perusahaan dengan tingkat kesehatan yang sehat adalah Bank BCA dan Bank CIMB Niaga. Kemudian peringkat ketiga yang memiliki tingkat kesehatan yang cukup sehat adalah Bank Danamon dan Bank Mandiri. Peringkat pertama yang memiliki tingkat kesehatan yang sangat sehat pada tahun 2019 adalah Bank BRI. Peringkat kedua pada tahun 2019 yang artinya perusahaan dengan tingkat kesehatan yang sehat adalah Bank Negara Indonesia, Bank BCA dan Bank CIMB Niaga. Kemudian peringkat ketiga pada tahun 2019 yang memiliki tingkat kesehatan yang cukup sehat adalah Bank Mandiri dan Bank Danamon. 


\section{Good Corporate Governance}

Tabel 3. Peringkat Good Corporate Governance

\begin{tabular}{|c|l|c|c|c|c|}
\hline \multirow{2}{*}{ No. } & \multicolumn{2}{|c|}{ Jenis Bank Konvensional } & \multicolumn{4}{c|}{ Peringkat } \\
\cline { 3 - 6 } & & 2016 & 2017 & 2018 & 2019 \\
\hline 1. & Bank Central Asia & 1 & 1 & 1 & 2 \\
\hline 2. & Bank Rakyat Indonesia & 1 & 1 & 2 & 1 \\
\hline 3. & Bank CIMB Niaga & 2 & 2 & 2 & 2 \\
\hline 4. & Bank Mandiri & 1 & 1 & 1 & 1 \\
\hline 5. & Bank Negara Indonesia & 2 & 2 & 2 & 2 \\
\hline 6. & Bank Danamon & 2 & 2 & 2 & 2 \\
\hline
\end{tabular}

Sumber : Bursa Efek Indonesia

Sumber: Diolah Peneliti

Tabel 3 adalah hasil perhitungan yang dilakukan oleh masing-masing perusahaan sehingga dapat hasil yang telah dihitung dan akan mendapat peringkat sesuai dengan hasil akhir tersebut. Peringkat Pertama pada tahun 2016 untuk Good Corporate Governance yang memiliki tingkat kesehatan yang sehat adalah Bank BCA, Bank BRI dan Bank Mandiri.

Kemudian untuk Peringkat kedua pada tahun 2016 untuk Good Corporate Governance yang memiliki tingkat kesehatan yang pertama yang artinya tingkat kesehatan yang sangat sehat adalah Bank CIMB Niaga, Bank Negara Indonesia dan Bank Danamon. Kemudian untuk peringkat pertama pada tahun 2017 yang memiliki tingkat kesehatan yang sehat adalah Bank Central Asia, Bank BRI dan Bank Mandiri.

Kemudian untuk Peringkat Kedua pada tahun 2017 untuk Good Corporate Governance yang memiliki tingkat kesehatan yang sehat adalah Bank CIMB Niaga, Bank Negara Indonesia dan Bank Danamon. Kemudian untuk peringkat pertama pada tahun 2018 yang memiliki tingkat kesehatan yang sehat adalah Bank Central Asia dan Bank Mandiri.

Kemudian untuk peringkat 2 pada tahun 2018 adalah Bank BRI, Bank CIMB Niaga, Bank BNI dan Bank Danamon. Kemudian pada tahun 2019 Bank yang mendapat peringkat 1 adalah Bank BRI dan Bank Mandiri. Dan untuk peringkat kedua pada tahun 2019 adalah Bank Central Asia, Bank CIMB Niaga, Bank BNI dan Bank Danamon. 


\section{Return On Assets}

Tabel 4. Perhitungan dengan Menggunakan ROA

\begin{tabular}{|c|l|c|c|c|c|c|c|c|c|}
\hline \multirow{2}{*}{ No. Jenis Bank Konvensional } & \multicolumn{3}{|c|}{ Hasil Perhitungan ROA } & \multicolumn{4}{c|}{ Peringkat } \\
\cline { 3 - 10 } & & $\mathbf{2 0 1 6}$ & $\mathbf{2 0 1 7}$ & $\mathbf{2 0 1 8}$ & $\mathbf{2 0 1 9}$ & $\mathbf{2 0 1 6}$ & $\mathbf{2 0 1 7}$ & $\mathbf{2 0 1 8}$ & $\mathbf{2 0 1 9}$ \\
\hline 1. & Bank BCA & $4,1 \%$ & $4,1 \%$ & $4,2 \%$ & $4,2 \%$ & 1 & 1 & 1 & 1 \\
\hline 2. & Bank BRI & $3,6 \%$ & $3,5 \%$ & $3,4 \%$ & $3,2 \%$ & 1 & 1 & 1 & 1 \\
\hline 3. & Bank CIMB Niaga & $1,1 \%$ & $1,7 \%$ & $1,8 \%$ & $2,0 \%$ & 3 & 1 & 1 & 1 \\
\hline 4. & Bank Mandiri & $1,9 \%$ & $2,5 \%$ & $2,9 \%$ & $2,9 \%$ & 1 & 1 & 1 & 1 \\
\hline 5. & Bank BNI & $2,6 \%$ & $2,6 \%$ & $2,6 \%$ & $3,4 \%$ & 1 & 1 & 1 & 1 \\
\hline 6. & Bank Danamon & $2,4 \%$ & $2,8 \%$ & $2,7 \%$ & $2,9 \%$ & 1 & 1 & 1 & 1 \\
\hline
\end{tabular}

Sumber: Diolah Peneliti

Pada Tabel 4 merupakan hasil nilai yang telah dihitung dengan menggunakan rumus ROA sehingga dapat diketahui perusahaan yang memiliki tingkat kesehatan yang sangat sehat hingga perusahaan yang memiliki tingkat kesehatan yang kurang sehat. Dan diketahui bahwa peringkat pertama pada tahun 2016 yang memiliki tingkat kesehatan yang sangat sehat tersebut adalah Bank BRI, Bank BNI, Bank Mandiri, Bank Danamon dan Bank BCA. Kemudian peringkat ketiga pada tahun 2016 yang memiliki tingkat kesehatan yang cukup sehat adalah Bank CIMB Niaga. Kemudian pada tahun 2017 diketahui bahwa peringkat pertama yang memiliki tingkat kesehatan yang sangat sehat tersebut adalah Bank BRI, Bank BNI, Bank Mandiri, Bank Danamon, Bank BCA dan Bank CIMB Niaga. Kemudian pada tahun 2018 diketahui bahwa peringkat pertama yang memiliki tingkat kesehatan yang sangat sehat tersebut adalah Bank BRI, Bank BNI, Bank Mandiri, Bank Danamon, Bank BCA dan Bank CIMB Niaga. Dan Kemudian pada tahun 2019 diketahui bahwa peringkat pertama yang memiliki tingkat kesehatan yang sangat sehat tersebut adalah Bank BRI, Bank BNI, Bank Mandiri, Bank Danamon, Bank BCA dan Bank CIMB Niaga.

\section{Net Interest Margin}

Tabel 5. Perhitungan dengan menggunakan NIM

\begin{tabular}{|c|l|c|c|c|c|c|c|c|c|}
\hline \multirow{2}{*}{ No. } & \multirow{2}{*}{ Jenis Bank Konvensional } & \multicolumn{3}{|c|}{ Hasil Perhitungan NIM } & \multicolumn{4}{c|}{ Peringkat } \\
\cline { 3 - 10 } & & 2016 & 2017 & 2018 & 2019 & 2016 & 2017 & 2018 & 2019 \\
\hline 1. & Bank BCA & $7 \%$ & $6 \%$ & $6 \%$ & $6 \%$ & 1 & 1 & 1 & 1 \\
\hline 2. & Bank BRI & $7 \%$ & $6 \%$ & $7 \%$ & $6 \%$ & 1 & 1 & 1 & 1 \\
\hline 3. & Bank CIMB Niaga & $4 \%$ & $4 \%$ & $4 \%$ & $4 \%$ & 1 & 1 & 1 & 1 \\
\hline 4. & Bank Mandin & $6 \%$ & $5 \%$ & $5 \%$ & $5 \%$ & 1 & 1 & 1 & 1 \\
\hline 5. & Bank BNI & $6 \%$ & $4 \%$ & $4 \%$ & $4 \%$ & 1 & 1 & 1 & 1 \\
\hline 6. & Bank Danamon & $8 \%$ & $8 \%$ & $6 \%$ & $6 \%$ & 1 & 1 & 1 & 1 \\
\hline
\end{tabular}




\section{Sumber: Diolah Peneliti}

Pada Tabel 5 merupakan hasil nilai yang telah dihitung dengan menggunakan rumus ROA sehingga dapat diketahui perusahaan yang memiliki tingkat kesehatan yang sangat sehat hingga perusahaan yang memiliki tingkat kesehatan yang kurang sehat.. Dan dapat ketahui bahwa peringkat pertama pada tahun 2016 hingga 2019 seluruh bank mendapat peringkat 1 yang artinya bank memiliki tingkat kesehatan yang sangat sehat, bank tersebut adalah Bank BRI, Bank BNI, Bank Mandiri, Bank Danamon, Bank BCA dan Bank CIMB Niaga.

\section{Capital Adequacy Ratio}

Tabel 6. Perhitungan dengan menggunakan CAR

\begin{tabular}{|c|l|c|c|c|c|c|c|c|c|}
\hline \multirow{2}{*}{ No. Jenis Bank Konvensional } & \multicolumn{3}{c|}{ Hasil Perhitungan CAR } & \multicolumn{4}{c|}{ Peringkat } \\
\cline { 4 - 10 } & & 2016 & 2017 & 2018 & 2019 & 2016 & 2017 & 2018 & 2019 \\
\hline 1. & Bank BCA & $22 \%$ & $24 \%$ & $23 \%$ & $25 \%$ & 1 & 1 & 1 & 1 \\
\hline 2. & Bank BRI & $23 \%$ & $23 \%$ & $23 \%$ & $23 \%$ & 1 & 1 & 1 & 1 \\
\hline 3. & Bank CIMB Niaga & $17 \%$ & $18 \%$ & $19 \%$ & $21 \%$ & 1 & 1 & 1 & 1 \\
\hline 4. & Bank Mandiri & $24 \%$ & $24 \%$ & $23 \%$ & $24 \%$ & 1 & 1 & 1 & 1 \\
\hline 5. & Bank BNI & $21 \%$ & $20 \%$ & $20 \%$ & $21 \%$ & 1 & 1 & 1 & 1 \\
\hline 6. & Bank Danamon & $29 \%$ & $31 \%$ & $32 \%$ & $33 \%$ & 1 & 1 & 1 & 1 \\
\hline
\end{tabular}

Sumber : Diolah Peneliti

\section{Sumber: Diolah Peneliti}

Pada tabel 6 merupakan hasil perhitungan CAR dan juga telah disesuaikan dengan peringkat berdasarkan persentase setiap bank. Pada tahun 2016 Peringkat pertama untuk bank yang memiliki tingkat kesehatan yang sangat sehat adalah Bank BRI, Bank BNI, Bank Mandiri, Bank Danamon, Bank BCA dan Bank CIMB Niaga.

Kemudian pada tahun 2017 untuk peringkat pertama dengan tingkat kesehatan yang sangat sehat adalah Bank BRI, Bank BNI, Bank Mandiri, Bank Danamon, Bank BCA dan Bank CIMB Niaga. Kemudian pada tahun 2018 Peringkat pertama untuk bank yang memiliki tingkat kesehatan yang sangat sehat adalah Bank BRI, Bank BNI, Bank Mandiri, Bank Danamon, Bank BCA dan Bank CIMB Niaga. Dan pada tahun 2019 Peringkat pertama untuk bank yang memiliki tingkat kesehatan yang sangat sehat adalah Bank BRI, Bank BNI, Bank Mandiri, Bank Danamon, Bank BCA dan Bank CIMB Niaga.

\section{Kesimpulan}

Berdasarkan dari perhitungan yang dilakukan dengan menggunakan rumus RGEC dan telah melakukan penyesuaian peringkat maka tingkat kesehatan Bank secara keseluruhan dari RGEC yang sangat sehat atau Bank yang mendapatkan peringkat 1 adalah Bank Central Asia, Bank Rakyat Indonesia dan Bank Mandiri.Berdasarkan dari perhitungan yang dilakukan dengan menggunakan rumus RGEC dan telah melakukan 
penyesuaian peringkat maka tingkat kesehatan Bank secara keseluruhan dari RGEC yang sehat atau Bank yang mendapatkan peringkat 2 adalah Bank CIMB Niaga, Bank Negara Indonesia dan Bank Danamon

Berdasarkan dari perhitungan yang dilakukan dengan menggunakan rumus RGEC dan telah peneliti telah melakukan penyesuaian peringkat, maka tingkat kesehatan bank dari tahun pertahun dari tahun 2016 - 2019 memiliki peringkat yang sama. Peringkat 1 tahun 2016 - 2019 adalah Bank Central Asia, Bank Rakyat Indonesia dan Bank Mandiri. Berdasarkan dari perhitungan yang dilakukan dengan menggunakan rumus RGEC dan telah peneliti telah melakukan penyesuaian peringkat, maka tingkat kesehatan bank dari tahun pertahun dari tahun 2016 - 2019 memiliki peringkat yang sama. Peringkat 2 tahun 2016 - 2019 adalah Bank Negara Indonesia, Bank CIMB Niaga dan Bank Danamon.

Bagi Perusahaan, Penelitian ini dapat menjadikan faktor pertimbangan perusahaan perbankan dalam mengambil keputusan dengan melihat kesehatan perusahaan dengan menggunakan metode yang sudah tersedia. Bagi Peneliti selanjutnya dapat menjadikan penelitian ini sebagai referensi untuk melakukan penelitian yang memiliki kesamaan dalam mengukur kesehatan perusahaan. Bagi Pembaca, penelitian ini menambah wawasan bagaimana cara mengetahui kesehatan perusahaan dengan cara yang berbeda tanpa melihat laba perusahaan 


\section{BIBLIOGRAFI}

Alawiyah, Tuti. (2016). Analisis Penilaian Tingkat Kesehatan Bank Dengan Menggunakan Metode Rgec Pada Bank Umum Bumn Yang Terdaftar Di Bursa Efek Indonesia Tahun 2012-2014. Jurnal Pendidikan Dan Ekonomi, 5(2), 114-123. Google Scholar

Anggito, Albi, \& Setiawan, Johan. (2018). Metodologi penelitian kualitatif. CV Jejak (Jejak Publisher). Google Scholar

Budijanto, Didik. (2013). Populasi, Sampling, dan Besar Sampel. Kementerian Kesehatan RI. Google Scholar

Hadad, Muliaman D. (2017). Financial Technology (Fintech) di Indonesia. Kuliah Umum Tentang Fintech, Indonesia Banking School. Google Scholar

Husein, Arif Rachman, \& Hasib, Fatin Fadhilah. (2016). Tingkat Kesehatan Bank: Analisa Perbandingan Pendekatan CAMELS dan RGEC (Studi Pada Bank Umum Syariah Tahun Periode 2012-2014). Jurnal Ekonomi Syariah Teori Dan Terapan, 3(2), 99-113. Google Scholar

Izza, Aqidatul. (2017). Peran Historis Perbankan Dalam Perekonomian Indonesia. Dinar: Jurnal Prodi Ekonomi Syariah, 1(1), 20-43. Google Scholar

Manoppo, Heven, \& Arie, Fitty Valdi. (2016). Pengaruh struktur modal, ukuran perusahaan dan profitabilitas terhadap nilai perusahaan otomotif yang terdaftar di Bursa Efek Indonesia periode 2011-2014. Jurnal EMBA: Jurnal Riset Ekonomi, Manajemen, Bisnis Dan Akuntansi, 4(2). Google Scholar

Rachmawati, Yuni. (2019). Pengaruh Inflasi dan Suku Bunga Terhadap Harga Saham Pada Perusahaan Perbankan Yang Terdaftar Di LQ45 Bursa Efek Indonesia. Jurnal Media Akuntansi (Mediasi), 1(1), 66-79. Google Scholar

Riniwati, Harsuko. (2016). Manajemen Sumberdaya Manusia: Aktivitas Utama dan Pengembangan SDM. Universitas Brawijaya Press. Google Scholar

Situmorang, James Rianto. (2012). Pemanfaatan internet sebagai new media dalam bidang politik, bisnis, pendidikan dan sosial budaya. Jurnal Administrasi Bisnis, 8(1). Google Scholar

Syahid, Dwi Caesar Nawawi. (2016). Pengaruh faktor eksternal dan internal terhadap kredit bermasalah serta dampaknya terhadap Cadangan Kerugian Penurunan Nilai menurut PSAK 55. Perbanas Review, 2(1). Google Scholar

First publication right:

Jurnal Syntax Fusion: Jurnal Nasional Indonesia

This article is licensed under:

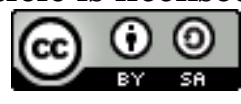

